\title{
AVAliaÇÃo dos PROdUTOS de EMISSÃo A PARTIR DA PIRÓlISE DE ASSENTOS AUTOMOTIVOS FEITOS DE FIBRA DE COCO E DE ESPUMA DE POLIURETANO
}

\section{EVALUATION OF EMISSION PRODUCTS FROM PYROLYSIS OF CAR SEATS MADE OF COIR FIBER AND OF POLYURETHANE FOAM}

\author{
Vera LúCIA PIMENTEl SALAZar \\ Bióloga pelo Instituto de Biociências da UNESP. Doutora em Agronomia pela Faculdade de Ciências \\ Agronômicas (FCA)/UNESP/Campus de Botucatu \\ JOSÉ CLÁUDIO CARASCHI \\ Químico, Professor, Doutor da Unidade Diferenciada de Itapeva/UNESP/Campus de Itapeva
}

\author{
ALCIDES LOPES LEÃO
}

Agrônomo, Professor Doutor do Departamento de Recursos Naturais da FCA/UNESP/Campus de Botucatu

Recebido: 04/10/04 Aceito: 20/04/05

\section{RESUMO}

O presente trabalho visa comparar assentos automobilísticos feitos de manta de fibra de coco com látex (MFCL) em relação à espuma de poliuretano (EPU), avaliando a possibilidade do primeiro substituir o segundo, devido ao fato da fibra natural ser biodegradável e renovável. Esses materiais foram submetidos à análise termogravimétrica (TGA), pirólise e análise dos produtos de pirólise por cromatografia gasosa acoplada ao espectrômetro de massa. Verificou-se que a pirólise a $800^{\circ} \mathrm{C}$ apresentou grande número de gases tóxicos, e comparando os materiais observou-se que a EPU emitiu gases mais tóxicos na combustão que aqueles produzidos pelos outros materiais sob as mesmas condiçôes, tais como o cianeto de hidrogênio e compostos de nitrila. Quanto às análises de TGA, verificou-se que acima de $270^{\circ} \mathrm{C}$ inicia-se a degradação térmica de todos materiais.

PALAVRAS-CHAVE: Pirólise, TGA, espuma de poliuretano, fibra de coco, manta de fibra de coco com látex, assentos automobilísticos.

\section{INTRODUÇÃO}

O uso de matérias-primas renováveis tem atraído a atenção de muitos pesquisadores, devido ao seu potencial para substituir derivados petroquímicos. A aplicação de fibras naturais como a fibra de coco, sisal, juta e outras fibras lignocelulósicas, como reforço de polímeros pode levar a materiais com boas propriedades mecânicas, térmicas, além de apresentar baixa densidade, flexibilidade, bio- degradabilidade e baixo custo (Bledzki \& Gassan, 1999; Bledzki, Reihmane \& Gassan, 1998; Rowell et al., 1997; Joseph et al., 2000; Guerreiro, 2000).

Dentre as fibras lignocelulósicas, a mais utilizada em assentos automobilísticos é a fibra de coco, sendo constituída quimicamente por $44,4 \%$ de celulose, $29,3 \%$ de lignina, $16,9 \%$ de pentosanas, $3,3 \%$ de cinzas e $0,4 \%$ de outros (sílica) (Han \& Rowell, 1997). A fibra de coco apresenta elasticidade e resistências ao desgaste, a umidade e à condiçôes climatológicas superiores às outras fibras vegetais (Harries \& Harries, 1976).

Segundo a Associação Brasileira da Agroindústria do Coco (ABRACOCO), o compósito de fibra de coco-látex apresenta várias vantagens em relação à espuma de poliuretano: ótima prontidão do motorista, ótima aeração, biodegradabilidade, reciclabilidade, custo equivalente ao da espuma, oito empregos/operação, produto renovável e combustão 
sem gases. Já a espuma, tem como características: baixa prontidão do motorista, baixa aeração, biodegradabilidade ou reciclabilidade, custo equivalente à fibra de coco, um emprego/operação, produto não renovável e combustão com muitos gases tóxicos, como por exemplo, o cianeto de hidrogênio (ABRACOCO). Além disso, as fibras vegetais apresentam vantagens como: baixa densidade, baixo consumo de energia, baixo custo, baixa abrasividade, atoxicidade, biodegradabilidade, reciclabilidade, boas propriedades mecânicas, geração de empregos rurais, utilização como reforço para vários tipos de plásticos e excelentes propriedades termoacústicas (Bledzki \& Gassan, 1999; Bledzki, Reihmane \& Gassan, 1998).

O presente trabalho visa comparar os materiais usados em assentos automobilísticos como a manta de fibra de coco com látex (MFCL) em relação à espuma de poliuretano (EPU), quanto às propriedades de queima, avaliando a possibilidade da fibra de coco (FC) substituir a espuma, devido ao fato de ser biodegradável, uma fonte renovável e geradora de pequenos danos desprezíveis ao meio ambiente. Esses materiais em estudo são componentes internos de veículos e a sua combustão não deve ser tóxica para não comprometer a saúde do usuário, em caso de incêndio do veículo. Por esse motivo, este estudo teve como objetivo a análise térmica por TGA e a análise qualitativamente dos produtos de pirólise a $500^{\circ} \mathrm{C}$ e $800^{\circ} \mathrm{C}$ da MFCL, da EPU e da FC, como referência.

\section{MATERIAIS E MÉTODOS}

As amostras de FC, MFCL e EPU foram analisadas por TGA e com relação aos seus produtos de pirólise, pela técnica de acoplamento pirólise/cromatografia gasosa/espectrometria de massa (Pir/GC/MS), que é uma das técnicas utilizadas na análise de polímeros (Jones \& Cramers, 1977). Esta técnica utiliza o fato de que a pirólise de polímeros não produz uma mistura aleatória de fragmentos.

As amostras foram inicialmente submetidas a um pirolisador de marca Shimadzu, modelo PYR-2A. A análise qualitativa dos produtos formados na pirólise dos materiais foi realizada num cromatógrafo gasoso de marca Shimadzu (modelo GC 9A), acoplado ao espectrômetro de massa de marca Shimadzu (modelo QP 1000A). A análise qualitativa dos produtos de pirólise foi efetuada a partir de 1,5 mg de amostra. As temperaturas de pirólise efetuadas foram de $500^{\circ} \mathrm{C}$ e $800^{\circ} \mathrm{C}$. As análises dos produtos da pirólise foram realizadas num cromatógrafo gasoso (GC) utilizando uma coluna do tipo Porapak Q nas seguintes condiçōes: hélio (He) como gás de arraste, fluxo de $20 \mathrm{~mL} / \mathrm{min}$ do gás de arraste, pressão de $0,5 \mathrm{kgf} / \mathrm{cm}^{2}$, aquecimento isotérmico a $50^{\circ} \mathrm{C}$ por 3 minutos, taxa de aquecimento de 50 a $220^{\circ} \mathrm{Ca} 10^{\circ} \mathrm{C} / \mathrm{min}$ e temperatura do injetor de $280^{\circ} \mathrm{C}$. O espectrômetro de massa (MS) foi utilizado nas seguintes condições: temperatura do separador e da fonte iônica de $300^{\circ} \mathrm{C}$ e energia a $70 \mathrm{eV}$.

As análises de TGA foram realizadas num aparelho termogravimétrico de marca Shimadzu, modelo TGA-50, sob atmosfera de ar, na faixa de temperatura de 25 a $800^{\circ} \mathrm{C}$, com taxa de aquecimento de $20^{\circ} \mathrm{C} / \mathrm{min}$.

\section{RESULTADOS E DISCUSSÕES}

\section{Análise qualitativa dos produtos formados na pirólise}

Os resultados da análise qualitativa dos produtos de pirólise a $500^{\circ} \mathrm{Ce} 800^{\circ} \mathrm{C}$ são apresentados nas Tabelas 1 e 2, respectivamente.

Observando os resultados da pirólise da MFCL em relação a FC (Tabela 1), verifica-se que nos produtos preponderantes da pirólise da MFCL aparece o isopreno, que é um constituinte do látex utilizado na fabricação das mantas, o qual apresenta 38,5\% de água, 60\% de poliisopreno (borracha) e 1,5\% de sais, resinas, cinzas e açúcares (Salazar, 2000). A FC apresenta como compostos caracte- rísticos o clorometano e o metanol; e a EPU apresenta propionaldeido e acrilonitrila.

Segundo Ramiah (1970), a pirólise, acima de $500^{\circ} \mathrm{C}$, garante que os principais compostos presentes nos materiais lignocelulósicos (lignina, celulose e pentosanas) sejam pirolisados. A pirólise final destes compostos ocorre ao redor de $380^{\circ} \mathrm{C}$ para a celulose, $440^{\circ} \mathrm{C}$ para a lignina e $320^{\circ} \mathrm{C}$ para as pentosanas.

Dentre os produtos detectados na pirólise dos materiais à $800^{\circ} \mathrm{C}$, pode ser destacado o benzeno e o tolueno que são produtos provenientes de todos os materiais analisados. Eles aparecem em pequenas proporçóes na EPU e como preponderantes na MFCL, sendo que na FC somente o benzeno aparece como preponderante (Tabela 2). Segundo os dados da literatura (MICROMEDEX, 1974-1999), a toxicidade aguda provocada pelo benzeno por inalação ou exposição da pele resulta em efeitos no Sistema Nervoso Central (SNC), queimação cutânea e efeitos respiratórios maléficos (pulmões hemorrágicos com pouco ar e edema pulmonar). A inalação pode resultar em irritação dos brônquios, tosse, rouquidão e edema Pulmonar. Quanto ao tolueno, sua exposição por inalação aguda pode resultar em irritação da laringe e brônquios, bronquite aguda, broncoespasmo, edema pulmonar e asfixia a partir de narcose e/ou sufocação. Um outro produto tóxico perigoso encontrado foi o monóxido de carbono (CO), cuja inalação pode levar a falhas respiratórias, dispnea ou edema pulmonar (MICROMEDEX, 1974-1999). Os efeitos neurológicos agudos incluem dor de cabeça, tonturas, mudanças sutis na personalidade, problemas de memória, confusão e coma (MICROMEDEX,

Tabela I - Resultados da análise qualitativa dos produtos de pirólise a $500^{\circ} \mathrm{C}$

\begin{tabular}{cccc}
\hline Material & \multicolumn{3}{c}{ Compostos } \\
& Preponderantes & Pequenas proporçōes & Traços \\
\hline FC & $\begin{array}{c}\text { Ácido acético, água, } \\
\text { dióxido de carbono }\end{array}$ & $\begin{array}{c}\text { Acetaldeído, acetona, } \\
\text { 2,3-butanodiona, } \\
\text { furano }\end{array}$ & $\begin{array}{c}\text { Acroleína, buteno, } \\
\text { clorometano, etileno, } \\
\text { metanol, propileno }\end{array}$ \\
MFCL & $\begin{array}{c}\text { Ácido acético, água, } \\
\text { dióxido de carbono, } \\
\text { isopreno }\end{array}$ & $\begin{array}{c}\text { Acetaldeído, acetona, } \\
\text { etileno, propileno, } \\
\text { buteno, furano } \\
\text { EPU }\end{array}$ & $\begin{array}{c}\text { Acroleína, etano, } \\
\text { 2,3-butanodiona }\end{array}$ \\
& $\begin{array}{c}\text { Acetaldeído, acetona, } \\
\text { dióxido de carbono, } \\
\text { propileno, } \\
\text { propionaldeido }\end{array}$ & acrilonitrila & Propano \\
& &
\end{tabular}


1974-1999). A maioria das vítimas de incêndios em ambientes fechados morre de envenenamento agudo por $\mathrm{CO}$, e não por queimaduras (Klaassen, 1996).

Comparando a pirólise a $800^{\circ} \mathrm{C}$ dos materiais MFCL e EPU quanto aos produtos formados, pode-se observar a presença do furano somente na MFCL. No entanto, todos os outros compostos que estão presentes na pirólise da MFCL também aparecem na EPU, sendo que esta ainda apresenta como compostos característicos o cianeto de hidrogênio, acetonitrila, acrilonitrila, propanonitrila e vinilacetonitrila. Dessa forma, pode-se afirmar que a fumaça formada pelos compostos resultantes da pirólise a $800^{\circ} \mathrm{C}$ da EPU é mais tóxica que aquela produzida pela MFCL sob as mesmas condiçōes.

Com relação à origem do furano presente na FC e MFCL, sabe-se que ele é formado a partir da desidratação das pentosanas presentes na $\mathrm{FC}$ que forma o furfural, e a oxidação deste origina o furano (Allinger et al., 1978). Quanto ao cianeto de hidrogênio (HCN) presente na pirólise a $800^{\circ} \mathrm{C}$ da espuma de poliuretano, sabe-se que é resultante da combustão de plásticos contendo grupos nitrila. Como exemplo prático, pode-se citar o acidente que ocorreu em Paris em 1973, onde um incêndio a bordo de um avião matou 119 passageiros, devido à combustão de material polimérico que produziu HCN (Klaassen, 1996).

$\mathrm{Na}$ Tabela 3 são apresentados os valores da IDLH (Concentração Imediatamente Perigosa para a Vida e Saúde) que indicam a concentração (em ppm) que representa o nível máximo de exposição em um período de 30 minutos em que uma pessoa pode escapar sem sintomas graves e efeitos irreversíveis para a saúde, segundo a NIOSH (Instituto Nacional para Segurança e Saúde Ocupacional, 1994), dos produtos encontrados na pirólise dos materiais em estudo.

Segundo os valores de IDLH dos compostos apresentados, nota-se que os mais prejudiciais à saúde em ordem decrescente são: cianeto de hidrogênio, ácido acético, acrilonitrila, benzeno, tolueno, monóxido de carbono e isopreno.

Comparando os resultados das análises das Tabelas 1 e 2 quanto aos compostos formados durante a pirólise, observa-se que na pirólise a $800^{\circ} \mathrm{C}$ foi produzido um maior número de compostos. Isso ocorre porque em altas temperaturas os compostos sofrem reaçôes químicas do tipo oxidação e/ou decomposição, origi-

Tabela 2 - Resultados da análise qualitativa dos produtos de pirólise a $800^{\circ} \mathrm{C}$

\begin{tabular}{|c|c|c|c|}
\hline \multirow[t]{2}{*}{ Material } & \multicolumn{3}{|c|}{ Compostos } \\
\hline & Preponderantes & Pequenas proporções & Traços \\
\hline FC & $\begin{array}{l}\text { Água, dióxido de } \\
\text { carbono, benzeno, } \\
\text { butadieno, buteno, } \\
\text { etileno, metano } \\
\text { propileno }\end{array}$ & $\begin{array}{l}\text { Acetaldeído, acetona, } \\
\text { etano, furano, } \\
\text { monóxido de carbono, } \\
\text { propenilacetileno, } \\
\text { tolueno }\end{array}$ & $\begin{array}{l}\text { Ácido acético, } \\
\text { acrilonitrila } \\
\text { metilacetileno }\end{array}$ \\
\hline MFCL & $\begin{array}{l}\text { Dióxido de carbono, } \\
\text { água, metano, etileno, } \\
\text { propileno, buteno, } \\
\text { butadieno, isopreno, } \\
\text { benzeno, tolueno }\end{array}$ & $\begin{array}{l}\text { Acetaldeído, etano, } \\
\text { metilacetileno, } \\
\text { monóxido de carbono }\end{array}$ & Acetona, furano \\
\hline EPU & $\begin{array}{l}\text { Dióxido de carbono, } \\
\text { etileno, metano, } \\
\text { propileno }\end{array}$ & $\begin{array}{l}\text { Água, acetaldeído, } \\
\text { acetonitrila, acetona, } \\
\text { acrilonitrila, benzeno, } \\
\text { buteno, butadieno, } \\
\text { monóxido de carbono, } \\
\text { tolueno }\end{array}$ & $\begin{array}{c}\text { Cianeto de } \\
\text { hidrogênio, isopreno, } \\
\text { propano, } \\
\text { propanonitrila, } \\
\text { vinilacetonitrila }\end{array}$ \\
\hline
\end{tabular}

nando outros compostos. Portanto, a queima destes materiais a $800^{\circ} \mathrm{C}$ acarreta em fumaça mais tóxica.

\section{Análise térmica por TGA}

A análise termogravimétrica (TGA) é definida como um processo contínuo que envolve a medida da variação de massa de uma amostra em função da temperatura (varredura de temperatura), ou do tempo a uma temperatura constante (modo isotérmico).

As curvas termogravimétricas obtidas para as amostras são apresentadas na Figura 1 e os resultados de perda de massa, na Tabela 4.

A Figura 1 mostra a curva termogravimétrica dos materiais. Três estágios de decomposição podem ser vistos, exceto na amostra de FC, que tem dois estágios e apresenta o menor resíduo entre as amostras: cerca de $1,71 \%$.

Quanto à perda de massa, a $\mathrm{FC}$ foi a que perdeu mais massa, seguida da EPU, MFCL e por último, o látex, com a menor perda de massa, isto pode ser devido aos compostos metálicos presentes na sua composição (Salazar, 2000), como, por exemplo, chumbo e zinco, que foram encontrados nas concentrações de $3,28 \mathrm{mg} / \mathrm{g}$ e $10,2 \mathrm{mg} / \mathrm{g}$, respectivamente, o que leva a um maior resíduo final e, explica também a maior quantidade de resíduo encontrado para MFCL, com relação à FC .

A curva TGA para FC é tipicamente aquela observada em fibras ligno- celulósicas (Mothé \& Araújo, 1998; Yap et al., 1991; Ahmad-Fuad et al., 1994), quando a pirólise dos componentes inicia-se a $290^{\circ} \mathrm{C}$ e termina ao redor de $450^{\circ} \mathrm{C}$, com perda de massa de $67 \%$. Já a MFCL iniciou a degradação em torno de $300^{\circ} \mathrm{C}$ finalizando em $445^{\circ} \mathrm{C}$ com perda de massa de 65\%. Nas amostras, a volatilização dos gases formados em reaçôes com oxigênio $\left(\mathrm{O}_{2}\right)$ do ar teve início ao redor de $250^{\circ} \mathrm{C}$, com máxima razão de perda de massa $(\% / \mathrm{min})$ registrada na faixa de 300 a $350^{\circ} \mathrm{C}$. Estes resultados permitem afirmar que em temperaturas acima de $290^{\circ} \mathrm{C}$, a FC e a MFCL começam a se decompor.

De acordo com os dados de Ramiah (1970), a pirólise da lignina, hemiceluloses e celulose ocorrem inicialmente em 200, 220 e $250^{\circ} \mathrm{C}$, respectivamente.

Portanto, a decomposiçáo das amostras começa a uma temperatura mais alta que a da EPU, sendo a FC e a MFCL termicamente mais estáveis que a EPU nas mesmas condiçôes. Em torno de $275^{\circ} \mathrm{C}$, a EPU começa a decompor, e essa decomposição inicial se estende até $380^{\circ} \mathrm{C}$, com perda de massa de $76,7 \%$. Dentre as amostras analisadas, o Látex é o material que apresentou maior estabilidade térmica e a EPU, o material de menor estabilidade.

O perfil da curva de decomposição da EPU obtido é típico dos polímeros de poliuretano (Mothé \& Araújo, 1998), com segmento rígido (uretano) se decompondo entre $240^{\circ} \mathrm{C}$ e $350^{\circ} \mathrm{C}$, antes do segmento flexível (poliéster). 
Tabela 3 - Concentração máxima (ppm) segundo a IDLH para os principais compostos encontrados durante a pirólise dos materiais (NIOSH, 1994)

\begin{tabular}{ccc}
\hline Compostos & IDLH (ppm) & Fontes \\
\hline Acetaldeído & Ca** $^{*}[2000]$ & FC, MFCL, EPU \\
Acetona & 2500 & FC, MFCL, EPU \\
Acetonitrila & 500 & EPU \\
Ácido acético & 50 & FC, MFCL, EPU \\
Acrilonitrila & Ca [85] & FC, EPU \\
Benzeno & Ca [500] & FC, MFCL, EPU \\
Butadieno & Ca [2000] & FC, MFCL, EPU \\
Cianeto de hidrogênio & 50 & EPU \\
Dióxido de carbono & 40000 & FC, MFCL, EPU \\
Furano* & --- & FC, MFCL \\
Isopreno & Ca [2000] & MFCL, EPU \\
Monóxido de carbono & 1200 & FC, MFCL, EPU \\
Tolueno & 500 & FC, MFCL, EPU \\
\hline * valor de IDLH ainda náo determinado. \\
** notaçâo "Ca": substância considerada um potencial carcinógeno \\
ocupacional.
\end{tabular}

Tabela 4- Análise termogravimétrica dos materiais

\begin{tabular}{cccccccccc}
\hline Amostra & \multicolumn{3}{c}{$\mathrm{T}\left({ }^{\circ} \mathrm{C}\right)$} & \multicolumn{6}{c}{ Perda de massa (\%) } \\
& $\mathrm{T}_{0}$ & $\mathrm{~T}_{\mathrm{f}}$ & $200^{\circ} \mathrm{C}$ & $250^{\circ} \mathrm{C}$ & $300^{\circ} \mathrm{C}$ & $400{ }^{\circ} \mathrm{C}$ & $500{ }^{\circ} \mathrm{C}$ & $600^{\circ} \mathrm{C}$ & $800^{\circ} \mathrm{C}$ \\
\hline FC & 287,72 & 448,72 & 3,92 & 4,65 & 12,10 & 58,30 & 76,75 & 98,27 & 98,29 \\
MFCL & 297,51 & 444,14 & 1,05 & 2,70 & 10,60 & 56,35 & 76,37 & 92,71 & 92,55 \\
LÁTEX & 369,73 & 528,52 & 0 & 0,43 & 5,83 & 25,30 & 55,75 & 68,51 & 68,74 \\
EPU & 276,20 & 382,46 & 0 & 2,00 & 21,54 & 80,80 & 89,39 & 96,80 & 97,88 \\
\hline
\end{tabular}

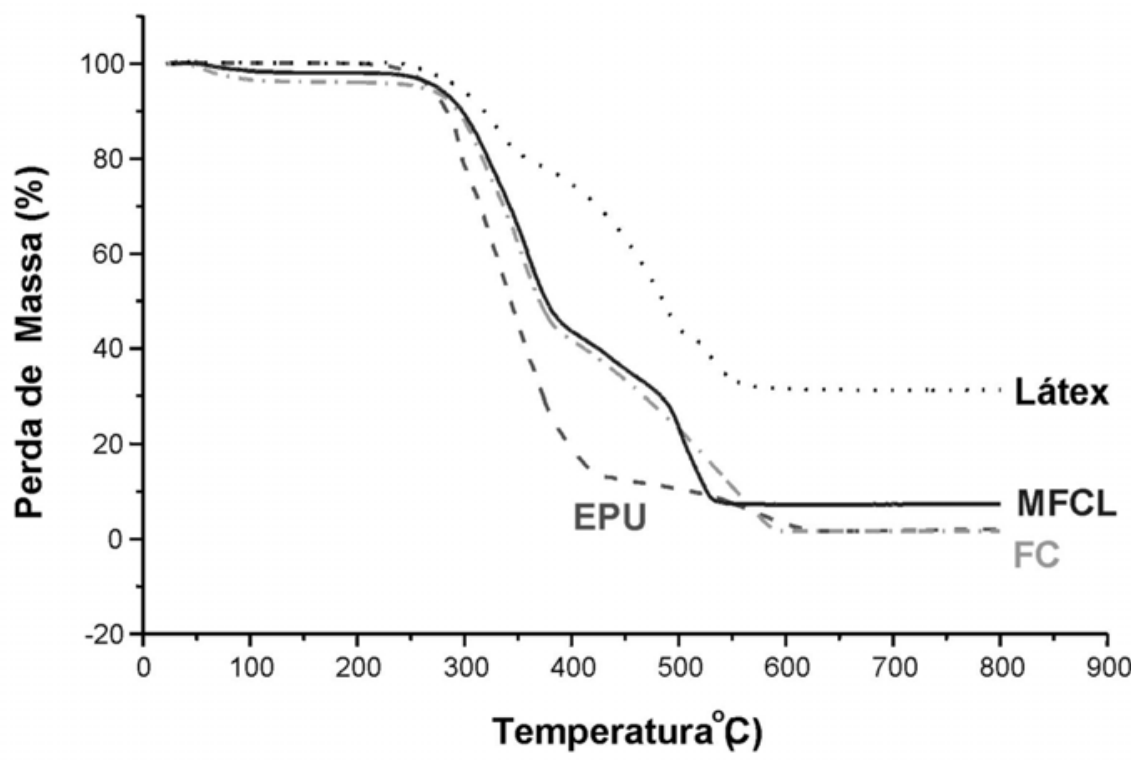

Figura I- Curva de TGA dos materiais: fibra de coco (FC), manta de fibra de coco com látex (MFCL), látex e espuma de poliuretano (EPU)

\section{CONCLUSÕES} se que:

A partir dos resultados concluiu-

A pirólise dos materiais a $800^{\circ} \mathrm{C}$ leva a um maior número de compostos e com maior toxicidade;

- A fumaça (gases) formada pelos compostos resultantes da pirólise da espuma de poliuretano é mais tóxica que aquela produzida pela manta de fibra de coco com látex nas mesmas condições;

- A combustão de ambos materiais provenientes de assentos automobilísticos, a espuma de poliuretano e/ou manta de fibra de coco com látex levam à formação de compostos de alta toxicidade quando queimados à $800^{\circ} \mathrm{C}$, sendo a espuma de poliuretano a que apresentou compostos de maior toxicidade;

- Com relação à estabilidade térmi$\mathrm{ca}$, a manta de fibra de coco com látex apresentou-se mais estável que a espuma de poliuretano.

\section{AGRADECIMENTOS}

Os autores deste trabalho agradecem a FAPESP pelo apoio financeiro, a MERCEDES-BENZ pelo fornecimento dos materiais, e a Dra. Elisabete Frollini e Eng. Jane M.F. Paiva do DFQ-IQSC-USP/ São Carlos pelas Análises Térmicas de TGA.

\section{REFERÊNCIAS}

AHMAD-FUAD, M.Y. et al. Determination of filler content in rice husk ash and wood-based composites by thermogravimetric analysis. Journal of Applied Polymer Science, v.51, n.11, p.1875-82, 1994.

ALLINGER, N.L. et al. Química Orgânica. 2.ed. Rio de Janeiro. Guanabara Dois, p.6867.1978 .

BLEDZKI, A.K. \& GASSAN, J. Composites reinforced with cellulose based fibres. Progress in Polymer Science, v.24, p.221-74, 1999.

BLEDZKI, A.K.; REIHMANE, S. \& GASSAN, J. Thermoplastics Reinforced with Wood Fillers: A Literature Review. Polymer-Plastic Technology, v.37, n.4, p.451-68, 1998.

GUERREIRO, A.R. Resinas e fibras alternativas aumentam o leque de opções de matériasprimas. Plástico Industrial, Ano.2, n.23, p.8095, Julho 2000.

HAN, J.S.; ROWELL, J.S. Chemical Compsosition of Fibers. In: Rowell, R.M.; Young, R.A.; Rowell, J.K. PAPER AND COMPOSITES FROM AGRO-BASED RESOURCES. Flórida, CRC Press, p.83-134. 1997.

HARRIES, N.G.; HARRIES, T.E. Materiais Têxteis: curso técnico programado. São Paulo, EEPU, 87p. 1976. 
JONES, R.W. \& CRAMERS, C.A. Analytical Pyrolysis. Amsterdan, Elsevier Sci. EPUbl. Co., 1977.

JOSEPH, K. et al. Natural Fibers Reinforced Thermoplastic Composites. In: Frollini, E.; Leão, A.L.; Mattoso, L.H.C. NATURAL POLYMERS AND AGROFIBERS BASED COMPOSITES, 2000, São Carlos. Anais... São Carlos: CIPBrasil, Embrapa Instrumentação Agropecuária, 2000. Section II - Agrofibers Composites, p.159-201.

KLAASSEN, C.D. Agentes tóxicos ambientai não-metálicos. In: Goodman \& Gilman. As Bases Farmacológicas da Terapêutica. 9 ed. México. McGraw-Hill Interamericana Editores, p.1240-52. 1996.

MICROMEDEX. International Healthcare Series. CD-Rom. v.100, Anos 1974-1999.

MOTHÉ, C.G.; ARAÚJO, C.R. Thermal Properties of natural fiber-reinforced polyurethane composites.In: CONFERENCE OF THE NORTH AMERICAN THERMAL ANALYSIS SOCIETY, 26 ${ }^{\text {th }}, 1998$, Cleveland - Ohio. Proceedings... Cleveland - Ohio, p.260-5. 1998.
NIOSH (National Institute for Occupational Safety and Health), CDC (Centers For Disease Control and Prevention). NIOSH Pocket Guide to Chemical Hazards. USA: Department of Health and Human Services, p.20-340, 1994.

RAMIAH,M.V. Thermogravimetric and Differential Thermal Analysis of Cellulose, Hemicellulose, and Lignin. Journal of Applied Polymer Science, v.14, p.1323-37, 1970.

ROWELL, R.M. et al. Utilization of Natural Fibers in Plastic Composites: Problems and Opportunities. In: Leão, A.L.; Carvalho, F.X. \& Frollini, E. Lignocellulosic-Plastic Composites. São Paulo. USP \& UNESP, p.23-51. 1997.

SALAZAR, V. L. P. Subsidios para análise do ciclo de vida de assentos à base de fibra de coco e látex. 131f. Dissertação (Mestrado) - Faculdade de Ciências Agronômicas, Universidade Estadual Paulista (UNESP). Botucatu - SP. 131 p. 2000.

YAP, M.G.S. et al. Thermal properties of tropical wood-polymer composites. Journal of Applied Polymer Science, v.43, n.11, p.2057-65, 1991.

\section{Endereço para correspondência:}

Vera Lúcia Pimentel Salazar

Departamento de Recursos

Naturais

Faculdade de Ciências

Agronômicas - UNESP

Cx. Postal 237

I 8603-970 Botucatu - SP - Brasil

Telefax: (I4) 38II-7I 63 - 7202

E-mail:vlpsalazar@hotmail.com 